\title{
Clinical effect of preoperative high-dose atorvastatin against no-reflow after PCI
}

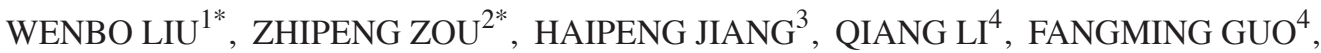 \\ ZHEN WANG ${ }^{4}$ and $\mathrm{HONGGUANG} \mathrm{ZHU}^{5}$ \\ ${ }^{1}$ Yantaishan Hospital; ${ }^{2}$ Department of Cardiology, Yeda Hospital of Yantai City; \\ Departments of ${ }^{3}$ Minimally Invasive Surgery and ${ }^{4}$ Cardiology, Yantaishan Hospital; \\ ${ }^{5}$ Department of Cardiology, Haigang Hospital of Yantai City, Yantai, Shandong 264001, P.R. China
}

Received May 6, 2016; Accepted October 27, 2016

DOI: $10.3892 /$ etm.2016.3910

\begin{abstract}
The aim of the present study was to evaluate the use of preoperative high-dose atorvastatin to prevent the no-reflow phenomenon after percutaneous coronary intervention (PCI). A total of 138 patients with ST-segment elevation myocardial infarction, admitted from March 2014 to January 2015, were enrolled and randomly divided into 3 groups of 46 individuals each. The groups included a control group in which patients were not treated with atorvastatin before PCI; a conventional-dose atorvastatin treatment group in which patients received a single dose of $20 \mathrm{mg}$ at bedtime one day prior to PCI; and a high-dose atorvastatin treatment group in which patients were treated with $40 \mathrm{mg}$ divided in two doses the day before PCI. The treatment effects were assessed by re-examining the echocardiography, high-sensitivity C-reactive protein and brain natriuretic peptide (BNP) levels after the PCI. The follow-up examinations included determinations of ultrasound imaging indicators and the contact with patients was maintained for a whole year. The CTFC (frame), pro-BNP, CK-MB peak and WMSI levels of the patients in the high-dose treatment group were significantly lower than those in the conventional dose or the control group. Trombolysis in myocardial infarction $\leq 2$ and myocardial blush grade $\leq 1$ levels were significantly lower than those in the conventional dose group $(\mathrm{P}=0.01)$ or those in the control group $(\mathrm{P}=0.01)$, although the echocardiographic indicators of the three groups were not significantly different $(\mathrm{P}<0.05)$. Nevertheless, it was found that there were significantly fewer adverse cardiovascular events in the high-dose group ( $\mathrm{P}<0.05$ in both cases). During the follow-up period, thromboembolism and restenosis were most infrequent in the
\end{abstract}

Correspondence to: Dr Hongguang Zhu, Department of Cardiology, Haigang Hospital of Yantai City, 100 Xingfu Road, Yantai, Shandong 264001, P.R. China

E-mail: zhu_hongguang1@163.com

Key words: acute coronary syndrome, emergency percutaneous coronary intervention, atorvastatin, cardiac remodeling high-dose atorvastatin group. Based on our findings the oral administration of high-dose atorvastatin before bedtime, one day before the procedure, can effectively prevent no-reflow cases, reduce adverse events and improve the long-term prognosis for acute coronary syndrome patients after PCI.

\section{Introduction}

At present the main pathological characteristics of acute coronary syndrome (ACS) are thought to include: i) Complete or incomplete atherosclerotic plaque rupture; ii) complete or incomplete obstructive pulmonary thromboembolism; and iii) acute myocardial ischemia or insufficient blood supply. ACS is clinically classified into acute myocardial infarction (AMI) and unstable angina (UA) (1-3). In the diagnosis of AMI, the AMI is further subdivided according to electrocardiogram findings in acute ST-segment elevation myocardial infarction (STEMI) and non-STEMI (NSTEMI) (4). NSTEMI and UA are also collectively referred to as non-ST-segment elevation ACS (NSTE-ACS) (5).

For patients with STEMI, early and rapid acute thrombolysis/therapeutic intervention [percutaneous coronary intervention (PCI)] and revascularization of blocked coronary arteries can significantly reduce mortality and improve the prognosis. However, after PCI, a no-reflow phenomenon may occur; in these cases it is not possible to restore the blood flow to a tissue even though the coronary arteries are made patent again, and the mechanism involves blockage of much smaller vessels irrigating the ischemic tissue (6-8). The no-reflow situation often appears after elective PCI, which may seriously affect the prognosis of patients $(7,9)$. This study evaluated a treatment with oral administration of high-dose $(0.4 \mathrm{mg} / \mathrm{kg} / \mathrm{day})$ atorvastatin instead of 3-hydroxy3-methylglutaryl-coenzyme A (HMG-CoA) for the STEMI patients before PCI and the treatment effect of the conventional-dose atropine atorvastatin and no use of atorvastatin before operation.

The aim of the present study was to evaluate the use of preoperative high-dose atorvastatin to prevent the no-reflow phenomenon after percutaneous coronary intervention (PCI). The results showed that, oral administration of high-dose atorvastatin before bedtime can effectively prevent no-reflow 
Table I. Basic information for 138 patients in emergency PCI of ACS.

\begin{tabular}{|c|c|c|c|c|c|c|}
\hline \multirow[b]{2}{*}{ Groups } & \multicolumn{2}{|c|}{ Gender } & \multirow[b]{2}{*}{ Age (years) } & \multirow{2}{*}{$\begin{array}{l}\text { Operation time } \\
\quad \text { (time/min) }\end{array}$} & \multirow{2}{*}{$\begin{array}{l}\text { Blood loss during } \\
\text { operation }(\mathrm{V} / \mathrm{ml})\end{array}$} & \multirow{2}{*}{$\begin{array}{l}\text { Length of stay in the } \\
\text { hospital (time/day) }\end{array}$} \\
\hline & Male & Female & & & & \\
\hline Control & 22 & 24 & $61.8 \pm 4.6$ & $45.2 \pm 12.6$ & $56.4 \pm 4.7$ & $8.8 \pm 1.3$ \\
\hline High-dose & 20 & 26 & $57.8 \pm 6.4$ & $50.3 \pm 11.9$ & $58.3 \pm 3.9$ & $7.4 \pm 1.2$ \\
\hline Conventional dose & 27 & 19 & $62.3 \pm 3.7$ & $46.8 \pm 10.7$ & $48.1 \pm 4.3$ & $7.1 \pm 0.8$ \\
\hline
\end{tabular}

PCI, percutaneous coronary intervention; ACS, acute coronary syndrome.

cases, reduce adverse events and improve the long-term prognosis for acute coronary syndrome patients after PCI.

\section{Patients and methods}

Inclusion and exclusion criteria. The inclusion criteria were: Patients in the group had to meet the STEMI diagnostic criteria developed by the American College of Cardiology (ACC) and the American Heart Association (AHA) (3), all patients had varying degrees of typical precordial pain or discomfort, and were diagnosed as STEMI through ECG, cardiac troponin markers, and other related examinations; the patients or their families signed informed consent (1).

Exclusion criteria were chosen based on another study (7) and included: Added cardiovascular diseases combined such as endocarditis, valvular disease or congestive heart failure; patients using immunosuppressive agents; patients with acute and chronic bacterial and/or viral infections; patients with autoimmune diseases; patients with connective tissue diseases; patients with malignant tumors; patients with liver or kidney dysfunction; patients with chronic muscle diseases; patients suffering from atorvastatin allergy; patients with peripheral vascular disease, chronic heart failure, thyroid disease, liver and kidney dysfunction, cancer, and major trauma; patients with myocardial infarction, percutaneous coronary angioplasty, coronary artery bypass graft surgery history during the recent 6 months, recent use of adrenocortical hormone or other immunomodulatory agents, non-compliant patients (or their families), and patients with a history of mental illness (2).

The no-reflow phenomenon (9) was identified in patients with anterograde flow $\leq 2$ levels for trombolysis in myocardial infarction (TIMI), and $\leq 1$ level for myocardial blush grade (MBG) in an infarct-related artery (IRA) and in the absence of dissection, thrombus, spasm or distal embolization after PCI.

$M B G(7)$. The myocardial blush was graded according to the contrast agent: 0 , no myocardial blush; 1 , mild myocardial blush; 2 , moderate myocardial blush, lightly blushed compared to the contralateral non-compromised side; and 3, normal myocardial blush, compared to the contralateral non-compromised area.

TIMI (10). The myocardial perfusion grading method was defined as: 0 , no myocardial filling and no evacuation; 1 , a slow myocardial filling, with very slow emptying, and a long contrast agent retention time that was still visible until the next angiography ( $\sim 30 \mathrm{sec}) ; 2$, partial myocardial filling, slow emptying myocardial blush which was still strong at the end of the washout period (i.e., after three cardiac cycles of the washout period); and 3, normal myocardial filling and emptying that were rapid, and in which the contrast agent had completely disappeared or rarely left at the end of the washout.

Clinical data. The 138 patients with ACS admitted during the period March 2014 to January 2015 who were enrolled as the study objects, included 78 males and 60 females, aged $28-87$ years (61.2 \pm 4.7 years on average). The enrolled patients were divided into the control group, conventional-dose atorvastatin group and high-dose atorvastatin treatment group in accordance with a computer-generated random numbers. The basic characteristics such as age, gender, duration of surgery, blood loss, and length of stay of the three groups were not significantly different $(\mathrm{P}>0.05)$ (Table I).

Treatment scheme. The patients were divided into three groups with 46 patients in each group. Patients in the control group did not receive atorvastatin for at least one week before the PCI. The patients in the conventional treatment group received $20 \mathrm{mg}$ oral atorvastatin (AstraZeneca, London, UK) once the night before the operation. The high-dose atorvastatin treatment group patients received $40 \mathrm{mg}$ atorvastatin divided in two doses the day before the PCI (11). During the course of 12 weeks, close monitoring was conducted on the patients' dynamic changes of creatine kinase (CK-MB), pro-brain natriuretic peptide (BNP), and other indicators, a total followup period of one year was achieved by keeping a telephonic communication with the patients.

\section{Observation indicators.}

PCI operation method. A thrombus aspiration catheter was used for repeated aspiration in the IRA lesion segment 3-5 times or more as appropriate to effectively remove the thrombus, clearing most of the intracoronary thrombus, contrast agent and distal embolization fragments. The time-lapse imaging was conducted after injection of 50-100 $\mu \mathrm{g}$ nitroglycerin in the coronary artery. With reference to the vessel diameter, when the residual stenosis was $<70 \%$ or the stent could pass through successfully, the stent implantation was carried out or moderate pressure (5-14 atm) was to be applied on the sacculus to achieve prior dilation. During the whole operation, before stent implantation or sacculus pre-dilation, the amount of contrast agent was controlled, to keep the contrast at the minimum needed and delay the interval between two radiographies. The epicardial blood vessels, and myocardial perfusion levels were assessed immediately after the operation: Two experienced interventional cardiologists analyzed IRA TIMI flow grades, TIMI frame counts (CTFC) and MBG. 
Table II. Comparison of echocardiographic indicators for the patients in the two groups before and after the treatment (mean \pm SD).

\begin{tabular}{llccr}
\hline Indicator & \multicolumn{1}{c}{ Groups } & Case no. & Before PCI & After PCI \\
\hline pro-BNP (ng/dl) & Control & 46 & $487.8 \pm 21.8$ & $257.2 \pm 16.8^{\mathrm{a}}$ \\
& High-dose & 46 & $597.4 \pm 64.5$ & $121.7 \pm 31.5^{\mathrm{b}}$ \\
& Conventional-dose & 46 & $512.6 \pm 85.3$ & $209.6 \pm 17.8^{\mathrm{c}}$ \\
CK-MB (U/l) & Control & 46 & $597.6 \pm 37.8$ & $473.8 \pm 21.5^{\mathrm{d}}$ \\
& High-dose & 46 & $502.5 \pm 16.5$ & $112.7 \pm 16.5^{\mathrm{e}}$ \\
& Conventional-dose & 46 & $511.4 \pm 25.6$ & $245.2 \pm 16.1^{\mathrm{f}}$
\end{tabular}

${ }^{\mathrm{a} C}$ Comparison of values before and after PCI, $\mathrm{P}<0.05$; ${ }^{\mathrm{b}}$ Comparison of values before and after PCI, $\mathrm{P}<0.001$; ${ }^{\mathrm{c}}$ comparison of values before and after PCI, $\mathrm{P}<0.01$; ${ }^{\mathrm{d}}$ comparison of values before and after PCI, $\mathrm{P}<0.05$; ${ }^{\mathrm{e}}$ comparison of values before and after PCI, $\mathrm{P}<0.001$; ${ }^{\mathrm{f}}$ comparison of values before and after PCI, $\mathrm{P}<0.01$. PCI, percutaneous coronary intervention; BNP, brain natriuretic peptide.

Serological testing. Venous blood (4-6 ml) was collected from the cubital fossa of patients in all the groups. For tests on the ultra-sensitivity C-reactive protein (CRP) $(3,4)$, pro-BNP $(3,5)$ and other biochemical markers, blood was collected after $8 \mathrm{~h}$ of fasting, and $2 \mathrm{ml}$ was used in a rapid fluorescence immunoassay (Triage tester) to obtain pro-BNP levels, and the remaining 2-4 $\mathrm{ml}$ were centrifuged for $10 \mathrm{~min}$ at $1,000 \mathrm{x} \mathrm{g}$, to separate the serum which was stored at $-80^{\circ} \mathrm{C}$ until its use in an enzyme-linked immunosorbent assay for obtaining pro-BNP levels.

Echocardiography test. A Philips IE33 (probe frequency 2.5 MHz) color Doppler ultrasound diagnostic apparatus was used for echocardiogram examinations of patients in all groups, before the operation, the day after the procedure and during the follow-up period. Parameters such as left ventricular end-diastolic diameter (LVEDD), left ventricular end-systolic diameter (LVESD) and left ventricular ejection fraction (LVEF) were recorded for statistical analyses.

Statistical analysis. SPSS19.0 was used for statistical analysis (Chicago, IL, USA). The $\chi^{2}$ test was used for the analysis of qualitative data, Fisher's exact probability method was used for the 4-fold table data not meeting the conditions. The quantitative data comparisons were carried out with analysis of variance. $\mathrm{P}<0.05$ was considered to indicate a statistically significant difference.

\section{Results}

Comparison of biochemical indicators after surgery. After PCI, the pro-BNP and CRP levels in the three groups were all decreased after the procedure. However, the difference in levels in the high-dose treatment group was the largest and it was statistically significant $(\mathrm{P}<0.05)$. The CK-MB peak levels of the patients in the three groups were decreased after the PCI, but again, the effect was significantly larger in the patients of the high-dose treatment group $(\mathrm{P}<0.05)$ (Table II).

Comparison of echocardiographic indicators after treatment. After PCI, the LVEDD of the patients in the three groups was decreased significantly compared to that before PCI, but there were no statistically significant differences among the three groups. The left ventricular end-systolic diameter (LVESD) and LVEF were significantly increased for the patients in the three groups after the treatment. However, the differences were not statistically significant among the groups (Table III).

Epicardial blood vessels, and myocardial perfusion levels immediately after the operation. Studies on blood perfusion levels for the patients in the three groups immediately after the operation, found that the CTFC (frame) and WMSI levels for the patients in the high-dose treatment group were significantly lower than those in the conventional dose and control groups (Table IV). The $\leq 2$ TIMI and $\leq 1 \mathrm{MBG}$ levels were significantly lower than those in the conventional dose group $(\mathrm{P}=0.01)$ or the conventional treatment group $(\mathrm{P}=0.01)$ (Table $\mathrm{V})$.

Treatment effect. Except for the fact that a few cases in the three groups developed dizziness and palpitations during the drug administration process, there were no significant adverse reactions and liver and kidney dysfunctions remained normal. The patients in the three groups were followed up after the operation by telephone or SMS text messaging. Complications and negative outcomes during the one year follow-up period, such as occurrence of re-stenosis, death, non-fatal myocardial infarction, and cardiogenic shock in the high-dose atorvastatin group were significantly less frequent compared with those occurring in the conventional-dose atorvastatin or the control group and the differences wre statistically significant in both cases $(\mathrm{P}<0.05)($ Table VI).

\section{Discussion}

No-reflow after PCI is a common complication, which mainly refers to the process in which blood supply to the tissues cannot be immediately restored after coronary blood flow recanalization $(10,11)$. The specific mechanism for its occurrence is still not entirely clear, and it is believed at present that PCI with no reflow is related to micro-distal embolization, ischemia and reperfusion injury susceptibility. The incidence of no-reflow after PCI is high, and for susceptible patients the incidence is as high as $40 \%$ or more (12), which seriously affects the quality of life and prognosis of the patients (13-15). For the treatment on no-reflow after PCI, there are no effective approaches. In the latest guidelines, the treatment for no-reflow with the application of adenosine, sodium nitroprusside or other 
Table III. Comparison of echocardiographic indicators for the patients after the treatment (mean \pm SD).

\begin{tabular}{llccc}
\hline Indicator & \multicolumn{1}{c}{ Groups } & Case no. & Before PCI & After PCI \\
\hline LVEDD (mm) & Control & 45 & $59.3 \pm 5.3$ & $54.2 \pm 2.0$ \\
& High-dose & 47 & $58.7 \pm 3.5$ & $52.0 \pm 1.8$ \\
& Conventional-dose & 45 & $58.2 \pm 2.8$ & 0.78 \\
F-value & & - & 0.44 & 0.52 \\
P-value & & - & $42.1 \pm 4.7$ & 0.35 \\
LVESD $(\mathrm{mm})$ & Control & 45 & $41.8 \pm 6.2$ & $40.2 \pm 1.3$ \\
& High-dose & 47 & $41.6 \pm 5.7$ & $39.6 \pm 1.8$ \\
F-value & Conventional-dose & 45 & 0.72 & $39.5 \pm 2.8$ \\
P-value & & - & 0.35 & 0.46 \\
LVEF $(\%)$ & & - & $45.9 \pm 4.2$ & 0.13 \\
& Control & 45 & $42.4 \pm 4.6$ & $49.2 \pm 5.5$ \\
F-value & High-dose & 47 & $46.3 \pm 8.5$ \\
P-value & Conventional-dose & 45 & 0.63 & $46.3 \pm 4.8$ \\
\hline
\end{tabular}

LVEDD, left ventricular end-diastolic diameter; LVESD, left ventricular end-systolic diameter; LVEF, left ventricular end-systolic diameter.

Table IV. Epicardial blood vessels, and myocardial perfusion levels immediately after the operation.

\begin{tabular}{llccc}
\hline Indicator & \multicolumn{1}{c}{ Groups } & Case no. & Before PCI & After PCI \\
\hline CTFC (frame) & Control & 46 & $59.3 \pm 5.3$ & $58.2 \pm 2.0$ \\
& High-dose & 46 & $58.7 \pm 3.5$ & $58.2 \pm 2.8$ \\
& Conventional-dose & 46 & 0.78 & $48.6 \pm 2.5$ \\
F-value & & - & 0.65 & 3.52 \\
P-value & & - & $42.1 \pm 4.7$ & 0.02 \\
WMSI (mm) & Control & 46 & $41.8 \pm 6.2$ & $40.2 \pm 1.3$ \\
& High-dose & 46 & $41.6 \pm 5.7$ & 0.72 \\
F-value & Conventional-dose & 46 & 0.35 \\
P-value & & - & $38.5 \pm 1.8$ \\
\hline
\end{tabular}

PCI, percutaneous coronary intervention.

vasodilators in the coronary artery and vein during the PCI currently belongs only to a class IIb indication (16). Effective strategies to prevent no-reflow phenomenon during PCI are being actively sought (17-19).

It is possible that there is a relationship between high serum lipoprotein levels and a hypercoagulable state and the phenomenon of non-reflow, as these circumstances are usually present in no-reflow cases. From the various lipid-lowering drugs, atorvastatin (20) is a selective and competitive HMG-CoA reductase inhibitor (21). The main indication for its use is the primary or mixed dyslipidemia of patients (22) that cannot be controlled through dietary, exercise and reasonable weight control measures. The main pharmacological actions of atorvastatin include: inhibition of the transformation from 3-hydroxy-3-methylglutaryl-coenzyme A into mevalonate in the liver (23) and an increase in the number of hepatic LDL cell surface receptors (8); and the promotion of LDL uptake and catabolism and inhibition of the liver synthesis of VLDL with reduction in the total number of VLDL and LDL particles (19).

In a previous clinical practice, it was found that the use of high-dose statins before an emergency PCI promote healing, improved prognosis and reduces the incidence of no-reflow phenomenon after PCI (24). It is generally assumed that the no-reflow phenomenon is due to thrombosis formation, embolism and elevated blood lipids in the local tissue microcirculation under infarction. The present study was carried out under the hypothesis that a high dose of atorvastatin prior to a PCI procedure could prevent the no-reflow phenomenon. It was found that in patients with PCI $24 \mathrm{~h}$ after treatment with high-dose atorvastatin, the CTFC (frame), pro-BNP, CK-MB peak and WMSI levels were significantly lower than the levels in those in the conventional dose or the control groups. The 
Table V. TIMI and MBG grading immediately after surgery.

\begin{tabular}{llcrc}
\hline \multirow{2}{*}{ Item } & \multicolumn{1}{c}{ Groups } & $\begin{array}{c}\text { No. of } \\
\text { cases }\end{array}$ & Yes & No \\
\hline \multirow{2}{*}{$\leq 2$ TIMI levels } & Control & 46 & 27 & 19 \\
& High-dose & 46 & 4 & 42 \\
& Conventional-dose & 46 & 11 & 35 \\
$\chi^{2}$ value & & - & \multicolumn{2}{c}{17.9} \\
P-value & & - & \multicolumn{2}{c}{0.01} \\
$\leq 1$ MBG level & Control & 46 & 22 & 24 \\
& High-dose & 46 & 3 & 43 \\
$\chi^{2}$ value & Conventional-dose & 46 & 9 & 37 \\
P-value & & - & \multicolumn{2}{c}{22.4} \\
\hline
\end{tabular}

TIMI, trombolysis in myocardial infarction; MBG, myocardial blush grade.

abovementioned studies showed that high-dose atorvastatin played an important role in inhibiting thromboembolism in the microcirculation, while the results of the present study seem to validate that finding as the occurrence of restenosis was lowest among the high-dose atorvastatin group. It it possible that high-dose atorvastatin can inhibit the formation of VLDL, significantly lower the serum cholesterol level and thereby improve microcirculation preventing thrombosis formation (10-13). In addition, it has also been observed in New Zealand rabbit models with myocardial ischemia, that a single dose of atorvastatin improves the myocardial no-reflow phenomenon by regulating the serum IL-6 and IFN- $\gamma$ levels (5). After the activation of IL-6 and IFN- $\gamma$, the NF- $\kappa$ B signaling pathway of myocardial cell is activated releasing various inflammatory cytokines, which further damage the myocardial tissue. However, high-dose atorvastatin can effectively inhibit the secretion of IL-6, stimulate the secretion of anti-inflammatory cytokine IL-10, and alter the TNF- $\alpha / \mathrm{IL}-10$ ratio after myocardial infarction. The regulation on these inflammatory cytokines has been shown to significantly improve the long-term ventricular remodeling and the LVEF after PCI $(14,15)$.

In addition, we found that $\leq 2$ TIMI and $\leq 1$ MBG levels after the operation in the high-dose group were significantly smaller than those in the conventional-dose $(\mathrm{P}=0.01)$ or the control $(\mathrm{P}=0.01)$ groups. Importantly, the rate of adverse cardiovascular events after the operation in the high-dose group were significantly less than those in the other two groups, and the differences were statistically significant. The TIMI flow grade was originally used to describe coronary artery blood flow after thrombolysis for AMI. It is assumed that a TIMI level $\leq 2$ can reflect a no-reflow phenomenon (13). In the case of the MBG grade, according to our method of grading using contrast agent, when $\mathrm{MBG}$ grade is $<\mathrm{I}$, it reflects an abnormal reflow (13). In the present study, the $\leq 2$ TIMI and $\leq 1 \mathrm{MBG}$ cases in the high-dose group were significantly less than those in the control group and the conventional-dose group. In our view, this was probably due to the improvement of lipid levels in the patients and to the reduction in the VLDL after the operation, which can effectively prevent thrombosis under microcirculation after STEMI.

Table VI. Comparison of the relevant follow-up data for the patients in the three groups after PCI (n, \%).

\begin{tabular}{|c|c|c|c|c|c|c|}
\hline Item & $\begin{array}{l}\text { Cases under } \\
\text { follow-up }\end{array}$ & $\begin{array}{l}\text { Control group } \\
\qquad(\mathrm{n}=46)\end{array}$ & $\begin{array}{l}\text { Conventional-dose } \\
\text { group }(n=46)\end{array}$ & $\begin{array}{l}\text { High-dose treatment } \\
\text { group }(n=46)\end{array}$ & F-value & $\mathrm{P}$-value \\
\hline $\begin{array}{l}\text { Occurrence of } \\
\text { re-stenosis one } \\
\text { year after the } \\
\text { follow-up visit }\end{array}$ & 138 & $18(0.40)$ & $16(0.36)$ & $5(0.11)$ & 3.21 & 0.03 \\
\hline $\begin{array}{l}\text { Death during the late } \\
\text { follow-up period }\end{array}$ & 138 & $6(0.13)$ & $2(0.04)$ & $1(0.02)$ & 2.25 & 0.02 \\
\hline $\begin{array}{l}\text { Occurrence of nonfatal } \\
\text { myocardial infarction } \\
\text { during the late } \\
\text { follow-up period }\end{array}$ & 138 & $9(0.20)$ & $6(0.13)$ & $2(0.04)$ & 3.78 & 0.02 \\
\hline $\begin{array}{l}\text { Occurrence of nonfatal } \\
\text { cardiac shock during the } \\
\text { late follow-up period }\end{array}$ & 138 & $1(0.02)$ & $0(0.00)$ & $0(0.00)$ & 7.82 & 0.01 \\
\hline $\begin{array}{l}\text { Blood circulation } \\
\text { remodeling in the } \\
\text { treated blood vessel } \\
\text { during the late } \\
\text { follow-up period }\end{array}$ & 138 & $11(0.24)$ & $21(0.47)$ & $39(0.83)$ & 4.82 & 0.03 \\
\hline
\end{tabular}

PCI, percutaneous coronary intervention. 
In the present study, we found that the echocardiographic indicators of some patients, shortly after the PCI were roughly equal to those before the operation and sometimes even worse after the operation, which may be due to the fact that cardiac remodeling after ACS is a slow recovery process, and although PCI re-canalization should improve the ischemia and hypoxic state and help to recover the myocardial function, the improvement in the ventricular morphology may not be detectable for some time. In agreement with this view, we found after the oneyear follow-up period that among the patients in the high-dose atorvastatin treatment group, the incidences of restenosis, death, nonfatal myocardial infarction, cardiogenic shock and other adverse events was significantly lower than the same incidences for the other patients. The results of the present study suggest that atorvastatin may improve the situation of no-reflow after PCI by lowering blood fat, improving blood sugar levels and regulating blood pressure indirectly. Further studies are required and an intravenous dose of atorvastatin may be a more useful approach in cases where a PCI is an emergency.

In conclusion, the administration of the high-dose atorvastatin to STEMI patients, at bedtime one day before PCI, can significantly improve the no-reflow phenomenon after recanalization, reduce the postoperative adverse events, and significantly improve the long-term prognosis.

\section{References}

1. Thygesen K, Alpert JS, Jaffe AS, Simoons ML, Chaitman BR, White HD, Thygesen K, Alpert JS, White HD, Jaffe AS, et al; Joint ESC/ACCF/AHA/WHF Task Force for Universal Definition of Myocardial Infarction; Authors/Task Force Members Chairpersons; Biomarker Subcommittee; ECG Subcommittee; Imaging Subcommittee; Classification Subcommittee; Intervention Subcommittee; Trials \& Registries Subcommittee; Trials \& Registries Subcommittee; Trials \& Registries Subcommittee; Trials \& Registries Subcommittee; ESC Committee for Practice Guidelines (CPG); Document Reviewers: Third universal definition of myocardial infarction. J Am Coll Cardiol 60: 1581-1598, 2012.

2. Braunwald E, Antman EM, Beasley JW, Califf RM, Cheitlin MD, Hochman JS, Jones RH, Kereiakes D, Kupersmith J, Levin TN, et al: ACC/AHA guidelines for the management of patients with unstable angina and non-ST-segment elevation myocardial infarction. A report of the American College of Cardiology/American Heart Association Task Force on Practice Guidelines (Committee on the Management of Patients with Unstable Angina). J Am Coll Cardiol 36: 970-1062, 2000.

3. Zamani P, Schwartz GG, Olsson AG, Rifai N, Bao W, Libby P, Ganz $\mathrm{P}$ and Kinlay S; Myocardial Ischemia Reduction with Aggressive Cholesterol Lowering (MIRACL) Study Investigators: Inflammatory biomarkers, death, and recurrent nonfatal coronary events after an acute coronary syndrome in the MIRACL study. J Am Heart Assoc 2: e003103, 2013.

4. Abdelmouttaleb I, Danchin N, Ilardo C, Aimone-Gastin I, Angioï M, Lozniewski A, Loubinoux J, Le Faou A and Guéant JL: C-Reactive protein and coronary artery disease: additional evidence of the implication of an inflammatory process in acute coronary syndromes. Am Heart J 137: 346-351, 1999.

5. Zhao XJ, Liu XL, He GX and Xu HP: Effects of single-dose atorvastatin on interleukin-6, interferon gamma, and myocardial no-reflow in a rabbit model of acute myocardial infarction and reperfusion. Braz J Med Biol Res 47: 245-251, 2014.

6. Zhao B, Li J, Luo X, Zhou Q, Chen $\mathrm{H}$ and Shi $\mathrm{H}$ : The role of von Willebrand factor and ADAMTS13 in the no-reflow phenomenon: After primary percutaneous coronary intervention. Tex Heart Inst J 38: 516-522, 2011.

7. Zhou SS, Tian F, Chen YD, Wang J, Sun ZJ, Guo J and Jin QH: Combination therapy reduces the incidence of no-reflow after primary per-cutaneous coronary intervention in patients with ST-segment elevation acute myocardial infarction. J Geriatr Cardiol 12: 135-142, 2015.
8. Jones PH, Davidson MH, Stein EA, Bays HE, McKenney JM, Miller E, Cain VA and Blasetto JW; STELLAR Study Group: Comparison of the efficacy and safety of rosuvastatin versus atorvastatin, simvastatin, and pravastatin across doses (STELLAR* Trial). Am J Cardiol 92: 152-160, 2003.

9. Wang JW, Chen YD, Wang CH, Yang XC, Zhu XL and Zhou ZQ: Development and validation of a clinical risk score predicting the no-reflow phenomenon in patients treated with primary percutaneous coronary intervention for ST-segment elevation myocardial infarction. Cardiology 124: 153-160, 2013.

10. Zhou H, He XY, Zhuang SW, Wang J, Lai Y, Qi WG, Yao YA and Liu XB: Clinical and procedural predictors of no-reflow in patients with acute myocardial infarction after primary percutaneous coronary intervention. World J Emerg Med 5: 96-102, 2014

11. Qi K, Li L, Li X, Zhao J, Wang Y, You S, Hu F, Zhang H, Cheng Y, Kang S, et al: Cardiac microvascular barrier function mediates the protection of Tongxinluo against myocardial ischemia/reperfusion injury. PLoS One 10: e0119846, 2015.

12. Uitterdijk A, Yetgin T, te Lintel Hekkert M, Sneep S, KrabbendamPeters I, van Beusekom HM, Fischer TM, Cornelussen RN, Manintveld OC, Merkus D, et al: Vagal nerve stimulation started just prior to reperfusion limits infarct size and no-reflow. Basic Res Cardiol 110: 51, 2015.

13. Ahn SJ, Park KH, Ryoo NK, Hong JH, Jung C, Yoon $\mathrm{CH}$, Han MK and Woo SJ: No-reflow phenomenon in central retinal artery occlusion: incidence, risk factors, and clinical implications. PLoS One 10: e0142852, 2015.

14. Shen Y, Wu H, Wang C, Shao H, Huang H, Jing H and Li D: Simvastatin attenuates cardiopulmonary bypass-induced myocardial inflammatory injury in rats by activating peroxisome proliferator-activated receptor $\gamma$. Eur J Pharmacol 649: 255-262, 2010.

15. Stumpf C, Petzi S, Seybold K, Wasmeier G, Arnold M, Raaz D, Yilmaz A, Daniel WG and Garlichs CD: Atorvastatin enhances interleukin-10 levels and improves cardiac function in rats after acute myocardial infarction. Clin Sci (Lond) 116: 45-52, 2009.

16. Małek LA, Śpiewak M, Kłopotowski M, Miśko J, Rużyłło W and Witkowski A: The size does not matter - the presence of microvascular obstruction but not its extent corresponds to larger infarct size in reperfused STEMI. Eur J Radiol 81: 2839-2843, 2012.

17. Maksimenko AV and Turashev AD: No-reflow phenomenon and endothelial glycocalyx of microcirculation. Biochem Res Int 2012: 859231, 2012.

18. Wang CH, Chen YD, Yang XC, Wang LF, Wang HS, Sun ZJ and Liu HB: A no-reflow prediction model in patients with ST-elevation acute myocardial infarction and primary drug-eluting stenting. Scand Cardiovasc J 45: 98-104, 2011.

19. Lee MG, Jeong MH, Ahn Y, Cho JG, Park JC, Kang JC, Chae SC, Hur SH, Hong TJ, Kim YJ, et al; Korea Acute Myocardial Infarction Registry Investigators: Comparison of paclitaxel-, sirolimus-, and zotarolimus-eluting stents in patients with acute ST-segment elevation myocardial infarction and metabolic syndrome. Circ J 75: 2120-2127, 2011.

20. Choi YH, Suh SH, Choi JS, Kim CS, Sim DS, Bae EH, Lim SY, Ma SK, Jeong MH and Kim SW; Korea Acute Myocardial Infarction Registry Investigators: Triple vs. dual antiplatelet therapy in patients with acute myocardial infarction and renal dysfunction. Circ J 76: 2405-2411, 2012.

21. Di Sciascio G, Patti G, Pasceri V, Gaspardone A, Colonna G and Montinaro A: Efficacy of atorvastatin reload in patients on chronic statin therapy undergoing percutaneous coronary intervention: Results of the ARMYDA-RECAPTURE (Atorvastatin for Reduction of Myocardial Damage During Angioplasty) Randomized Trial. J Am Coll Cardiol 54: 558-565, 2009.

22. Aung Naing K, Li L, Su Q and Wu T: Adenosine and verapamil for no-reflow during primary percutaneous coronary intervention in people with acute myocardial infarction. Cochrane Database Syst Rev 6: CD009503, 2013.

23. Blanco-Colio LM, Villa A, Ortego M, Hernandez-Presa MA, Pascual A, Plaza JJ and Egido J: 3-Hydroxy-3-methyl-glutaryl coenzyme a reductase inhibitors, atorvastatin and simvastatin, induce apoptosis of vascular smooth muscle cells by downregulation of Bcl-2 expression and Rho a prenylation. Atherosclerosis 161: 17-26 2002.

24. Clearfield M: Efficacy of atorvastatin reload in patients on chronic statin therapy undergoing percutaneous coronary intervention. Curr Atheroscler Rep 12: 8-10, 2010. 